\title{
Transtorno de déficit de atenção/ hiperatividade: uma análise histórica e social
}

\section{Attention Deficit Hyperactivity Disorder: a Social and Historical Analysis}

Rita Signor*

Universidade Federal de Santa Catarina (UFSC)

Florianópolis -Santa Catarina/Brasil

RESUMO: O objetivo deste artigo é refletir sobre o processo de patologização da educação por meio de análise de caso de uma menina com diagnóstico de Transtorno de Déficit de Atenção/Hiperatividade (TDAH). Os resultados apontam que os discursos que se instauram em torno do aluno considerado hiperativo/desatento terminam por comprometer sua subjetividade e aprendizagem, uma vez que ele passa a internalizar parte das percepçôes de seu grupo de convivência. Assumindo os postulados de Vygotsky (1984), de que as funções cognitivas se formam na vigência da intersubjetividade, e os de Bakhtin (2006), de que construímos nossa autoimagem em meio ao olhar do outro, somos levados a concluir que a criança não nasce TDAH, mas que pode manifestar sinais de desatenção/hiperatividade a depender da qualidade das interações sociais em que está inserida.

PALAVRAS-CHAVE: TDAH; patologização da educação; subjetividade; aprendizagem.

ABSTRACT: This paper aims at reflecting about the process of pathologization of education through the case study of a girl diagnosed with Attention Deficit Hyperactivity Disorder (ADHD). The results show that the discourses that are established around the student considered as hyperactive/inattentive end up compromising her subjectivity and learning, once she starts to internalize part of the perceptions of her living group. Based on the postulates of Vygotsky (1984), that cognitive functions are formed in the presence of intersubjectivity, and of Bakhtin (2006), according to whom we construct our self-image amid the gaze of the other, we are led to conclude that the child is not born $\mathrm{ADHD}$, but may show signs of inattention/hyperactivity depending on the quality of the social interactions he takes part in.

KEYWORDS: ADHD; pathologization of education; subjectivity; learning.

\footnotetext{
* Fonoaudióloga. Doutoranda em Linguística pela Universidade Federal de Santa Catarina.ritasignor@gmail.com
} 


\section{Introdução}

O Transtorno de Déficit de Atenção/Hiperatividade - TDAH - é um tema que gera controvérsia entre os pesquisadores da área da saúde. Pautados em um paradigma positivista/organicista, há os que defendem que o TDAH seja um transtorno neurobiológico, de base genética, responsável pelo surgimento de sintomas de hiperatividade, impulsividade e desatenção, que afetaria de 3 a $5 \%$ dos escolares. Em adendo, $10 \%$ da população mundial seria portadora desse mal. Conforme essa visão, o transtorno seria decorrente de um aporte insuficiente de determinados neurotransmissores ao cérebro, especialmente dopamina e norepinefrina. Tal ineficiência ocasionaria uma disfunção na parte frontal do cérebro, responsável, entre outras funções, pela inibição comportamental.

De acordo com Barkley (2006, p. 15), "o TDAH representa uma das razões mais comuns para o encaminhamento de crianças a profissionais de medicina e saúde mental devido a problemas de comportamento nos Estados Unidos, e é um dos transtornos psiquiátricos mais comuns na infância”. Acrescente-se que a situação do Brasil é semelhante à dos Estados Unidos, visto que somos o segundo maior consumidor mundial de um medicamento que tem por princípio ativo o Metilfenidato, o mais indicado para o controle dos "sintomas" de desatenção/hiperatividade, sendo os americanos os primeiros colocados.

Com relação às dificuldades escolares que acometeriam alunos considerados portadores de TDAH, os estudos (pautados no paradigma organicista) indicam taxas de prevalência de 10 a $92 \%$, conforme Barkley (2006). O autor acredita que tal discrepância se deve a dois fatores, a saber, os aspectos metodológicos, que se diferenciam entre as pesquisas, e que por essa razão geram diferenças nos resultados dos estudos, e a própria noção do que seja uma dificuldade de aprendizagem. No Brasil, as pesquisas também revelam divergências. Enquanto alguns pesquisadores (WAJNSZTEJN, 2012) apregoam taxas de $30 / 35 \%$ de problemas de aprendizagem associados ao suposto transtorno, outros trabalhos revelam que a maioria das crianças com TDAH tem dificuldades na escola. Na pesquisa de Silva (2006), por exemplo, a autora chegou ao percentual de $87,5 \%$ de dificuldades de leitura e escrita em crianças diagnosticadas com TDAH.

De outro lado estão pesquisadores que, alinhados à perspectiva sóciohistórica, preconizam que o chamado TDAH representa um processo de patologização da educação, isto é, de transformação de questôes sociais, 
educacionais e políticas em questões médicas. Nessa direção, Moysés (2001) afirma que não há qualquer comprovação sobre a existência desse transtorno. Tal fato pode ser observado pelo uso corrente da expressão "disfunção cerebral", 1 ao invés de "lesão", uma vez que não se verifica, em sujeitos com diagnóstico de TDAH, qualquer evidência de comprometimento cerebral. $\mathrm{O}$ diagnóstico é meramente clínico, pautado em um "sujeito mediano", padronizado segundo uma norma social. Ademais, contrapondo o fato de que $10 \%$ da população seria portadora do transtorno, diz Moysés: ${ }^{2}$

Em saúde nós não lidamos com porcentagem, quando falamos em porcentagem estamos nos referindo a problemas sociais, como verminose e desnutrição. Quando falamos em doença biológica, como seria essa [o TDAH], falamos da ordem de 1/100.000, 1/1.000.000 casos. $10 \%$ é assustador, é uma epidemia, uma epidemia de incapacidades.

Vejo em minha prática clínica que os "sintomas" que orientam o diagnóstico, tais como: "não presta atenção a detalhes", "evita tarefas que exijam esforço mental constante", "agita mãos ou pés e se remexe na cadeira”, "dá respostas precipitadas", "levanta-se da carteira quando não esperado", "fala em demasia”, "está a mil ou a todo vapor", entre outros, e que são frequentemente relatados pelos professores, muitas vezes não se evidenciam em situação clínica, o que me leva a questionar se, de fato, tais sinais não seriam construídos no espaço da escola. Percebo que as crianças não são desatentas e/ou hiperativas; são, sim, desinteressadas e manifestam uma relação de sofrimento com a escola. É possível, ao analisar os discursos dos educadores e as práticas pedagógicas a que a maioria das crianças é submetida, compreender os sinais de desinteresse apresentados.

Acrescente-se que muitas vezes a criança considerada hiperativa/ desatenta fica com a autoimagem distorcida, apresentando em seu discurso termos que foram internalizados do seu meio social: "não sei"; "não consigo"; "sou agitado"; "sou anormal"; "escrevo tudo errado"; "ninguém gosta de mim"; "detesto ler e escrever", etc. Assim, muitas vezes, existe um prejuízo real da

\footnotetext{
${ }^{1}$ A partir da década de 1950, a expressão "lesão cerebral" foi substituída por "disfunção cerebral".

${ }^{2}$ Maria Aparecida Affonso Moysés, pediatra, professora titular do curso de Medicina da UNICAMP. Orienta e desenvolve estudos na área da Saúde do Escolar. O trecho em destaque é parte de uma entrevista concedida pela professora ao GloboNews.
} 
aprendizagem e desenvolvimento na escola, não por conta de aspectos constitutivos à criança, ou seja, patológicos, mas por razões delegadas à esfera social/educacional - do próprio processo de patologização sofrido pela criança.

Vale mencionar que, conforme aponta Luria (1991), nos casos de patologias na área da atenção/comportamento, decorrentes de lesões verificáveis nos lobos frontais do cérebro, os sujeitos ficam impossibilitados de se concentrar na solução de uma tarefa e construir um sistema estável de relações seletivas relacionadas aos programas de ação. Desviam-se para os sinais secundários, frustrando sempre a atividade-alvo. Diz o autor que apesar da enorme heterogeneidade de manifestações dos distúrbios do comportamento, dois traços estão sempre presentes:

Em primeiro lugar, o comportamento do paciente deixa de ser controlado por um programa verbal motivado, ficando sob a influência de fatores interpostos e tornando-se mais primitivo em suas características. Em segundo lugar, mesmo quando o paciente conserva a formulação verbal correta da instrução (ela se torna distorcida ou desaparece apenas em pacientes com um tipo mais sério de lesão do lobo frontal), em geral ele nunca pode comparar seu desempenho atual com sua intenção original, não tem consciência dos erros que comete e não faz qualquer tentativa para corrigi-los (LURIA, 1988, p. 214).

O autor alerta que é preciso não confundir um estado patológico com as instabilidades da atenção, que ocorrem em condições não patológicas, como nas alteraçōes do sistema nervoso (estresse, estafa etc.). Nesses casos, a instabilidade pode ser superada por um esforço voluntário do sujeito, o que não ocorre nos estados patológicos. ${ }^{3}$ As consideraçóes do autor levam a entender que a desmotivação dos alunos diante das atividades desenvolvidas no contexto de suas escolas funcione como fonte de produção da maioria dos sinais apresentados. $\mathrm{O}$ sintoma da desatenção e hiperatividade que se produz em sala de aula é um construto histórico e social; faz parte do quadro das instabilidades atentivas presentes nessas condições não patológicas citadas por Luria (1988).

\footnotetext{
${ }^{3}$ Cabe ressaltar que no manual para o diagnóstico em psiquiatria há a menção de que, no caso do TDAH, os sintomas devem estar presentes em pelo menos dois contextos (casa e escola, por exemplo), o que indica que ora os sintomas estão presentes ora não estão. Esta é mais uma evidência de que o "transtorno" não deriva de uma disfunção cerebral, mas de aspectos contextuais/sociais. No caso de patologias na área do comportamento/atenção, os sintomas estão presentes em todos os contextos, segundo Luria.
} 
Desse modo, constatam-se duas manifestações distintas de um fenômeno: as patologias de comportamento/atenção, decorrentes de lesões na parte frontal do cérebro, como propõe Luria, e o TDAH-Social, construído no campo da escola, ou seja, oriundo de práticas pedagógicas inadequadas e de discursos depreciativos sobre o/para o aluno.

Ao afirmar que o problema é social, corroboro a visão de que a criança não é um organismo independente, isto é, não é um cérebro apartado das condições socioculturais que a cercam. O cérebro é um órgão dinâmico, flexível, que se modela na vigência das experiências de cada sujeito. Se acreditarmos, conforme Vygotsky (1984), que o cérebro se forma mediante a vida social do indivíduo, que, por sua vez, constitui seus processos cognitivos, somos levados a perceber a extrema influência da atividade intersubjetiva para a organização neurofuncional do cérebro. Assim, as funções cognitivas, quais sejam, a atenção, a percepção, a aprendizagem, entre outras, são adquiridas intersubjetivamente, por onde a linguagem exerce papel constitutivo. Podese afirmar, segundo esse ponto de vista, que a criança não nasce predestinada a ser desatenta ou hiperativa, mas pode se tornar "desatenta"/“hiperativa” em virtude da qualidade das interações em que está inserida.

Com relação ao tratamento, os pesquisadores organicistas preconizam uma terapêutica à base de medicamentos, especialmente estimulantes (metilfenidato), mas também são indicados, em larga escala, anfetaminas, antidepressivos, antipsicóticos etc. Para Connor (2006, p. 643), "atualmente os estimulantes de liberação imediata são prescritos três vezes por dia, ou são utilizados para complementar a ação de estimulantes de ação prolongada. Para reduzir o impacto geral do TDAH sobre o desenvolvimento de uma criança, os estimulantes são usados, muitas vezes, sete dias por semana, bem como durante os meses do verão".

Moysés, ${ }^{4}$ por seu turno, entende que o efeito-obediência, que ocorreria em virtude da ingestão de medicamentos, é chamado - na literatura farmacológica - de efeito-zumbi, que, como aponta a autora, é sinal de toxicidade, isto é, representa reaçóes adversas extremamente sérias que ocorrem em todos os sistemas do organismo. Ademais, os próprios pesquisadores organicistas citam os possíveis malefícios decorrentes do uso desses remédios: tiques, perda de peso, alteração de crescimento, sintomas gastrointestinais, problemas cardíacos, insônia, depressão, instabilidade do humor, ataques de

${ }^{4}$ Em entrevista concedida ao GloboNews. 
raiva, morte súbita, suicídio, psicopatias, entre outros. Questiono se para reduzir o impacto do chamado TDAH sobre o desenvolvimento de uma criança seria necessário medicá-la ou é possível criar condições sociais favoráveis para a sua aprendizagem e bom desenvolvimento?

O objetivo deste artigo é refletir sobre o processo de patologização da educação por meio de análise dos discursos que se instauram em torno da criança considerada hiperativa/desatenta. Para tanto, apresento parte da minha tese de doutorado, ${ }^{5}$ estudo em andamento. A hipótese desenvolvida é a de que os sinais de hiperatividade/desatenção, que levariam supostamente às dificuldades de aprendizagem, seriam construídos principalmente no espaço escolar e não decorreriam, portanto, de uma alteração orgânica. Desse modo, a criança, inserida em um processo de discursivização desfavorável no espaço da escola, acabaria internalizando parte do discurso alheio. Esse processo de internalização favoreceria a constituição de uma autoimagem rebaixada, trazendo implicações para os processos de aprendizagem. Interessa aqui analisar como esse processo de discursivização foi se formando ao longo da trajetória escolar da criança para poder compreender como os sintomas se constroem.

\section{Método}

Esta pesquisa se constitui em estudo de caso, pesquisa de campo, qualitativa, do tipo transversal, inserida em um paradigma teóricometodológico de cunho sócio-histórico. Pretende-se, por meio deste estudo, refletir sobre a seguinte pergunta: Como questôes sociais transformam-se em questôes de ordem biológica no espaço da escola e quais são as implicaçôes desse processo para a subjetividade e aprendizagem do aluno considerado hiperativo/desatento?

Para a tese, selecionou-se cinco alunos da rede pública de duas escolas de Florianópolis. Os critérios de seleção foram: alunos com diagnóstico médico de TDAH; crianças acima do terceiro ano do ensino fundamental (para que houvesse um volume suficiente de dados para melhor composição do

\footnotetext{
${ }^{5}$ Tese intitulada $O$ sentido do diagnóstico de Transtorno de Déficit de Atençãol Hiperatividade para a constituição do sujeitolaprendiz, sob orientação da Profa. Dra. Ana Paula Santana. Este estudo foi aprovado pelo Comitê de Ética da UFSC, sob processo 94.405/2012. Foram assinados os Termos de Consentimento Livre e Esclarecido por todos os sujeitos da pesquisa.
} 
"histórico"); e, por fim, que houvesse disponibilidade e interesse da família para a participação na pesquisa.

Para este artigo, apresento somente parte do caso de uma aluna (Susi) ${ }^{6}$ com diagnóstico de TDAH, 10 anos de idade, estudante do quinto ano do ensino fundamental (em 2012).

Os procedimentos da pesquisa envolveram: entrevistas com a mãe da criança e com a criança, avaliação fonoaudiológica individual, observação da aluna em sala de aula por um período de uma semana, entrevistas com professores e orientadora educacional, pesquisa documental (pareceres avaliativos da escola - atuais e pregressos, agendas, cadernos, livros, pastas com atividades), e avaliação das condições de letramento do grupo de alunos (avaliação de leitura e escrita de todos os alunos da sala). Os dados foram registrados por meio de gravação em áudio e diário de campo e analisados via dialogismo bakhtiniano (BAKHTIN, 2006).

A seguir, a apresentação do caso.

\section{Apresentando Susi}

Dos 2 aos 5 anos de idade, Susi frequentou, em período integral, uma escola de educação infantil pública. No primeiro e segundo ano do ensino fundamental, a menina estudou, também em período integral, em uma escola privada. Do terceiro ano aos dias atuais (quinto ano), estudou/a em uma escola da rede pública de ensino no período da manhã.

Susi realizou avaliação psicológica aos 5 anos de idade, pois havia queixas constantes da escola sobre o comportamento da menina, segundo palavras da mãe: "que a Susi não queria fazer as atividades, que a Susi não obedecia, que a Susi imitava ela [a professora], que a Susi brigava com os amigos...”. Aos 6 anos, a criança foi encaminhada para avaliação psiquiátrica, recebeu o diagnóstico de TDAH, indicação de tratamento medicamentoso, psicopedagógico e orientação de continuidade do atendimento psicológico, que realizava desde os 5 anos. Atualmente, Susi continua em atendimento psicológico, psiquiátrico e tomando medicação estimulante.

Cabe ressaltar que a criança teve dificuldades no processo de alfabetização. De acordo com a mãe, a filha conseguiu ser alfabetizada apenas no terceiro ano, pois teve "sorte", isto é, uma "professora maravilhosa". A sorte ocorreu porque naquele

${ }^{6}$ Os nomes utilizados neste trabalho são fictícios. 
ano se cessaram as reclamações sobre a criança e "qualquer coisa ela [a professora] elogiava, valorizava muito a produção deles... [dos alunos]”, completou a mãe.

A menina reside com a mãe em um apartamento de dois quartos em um condomínio de classe média em Florianópolis. Os pais de Susi são gaúchos e separados. À época da entrevista com a mãe, a separação havia ocorrido há quase dois anos. $\mathrm{O}$ pai, de 51 anos de idade, completou o ensino médio e trabalha na função de porteiro na cidade de Porto Alegre. A mãe, por sua vez, tem 52 anos de idade, é pedagoga aposentada, mas continua lecionando no período da manhã. Diz lecionar, ainda, por questôes financeiras, pois, segundo ela, "professor tem prazo de validade" e a atividade docente não lhe traz mais nenhum prazer.

Quanto à rotina, Susi acorda às 6:30h e após tomar café e se arrumar vai para a escola. Volta de ônibus para casa e fica esperando a mãe que trabalha no período da manhã. A menina permanece durante a tarde assistindo TV, ouvindo músicas, fazendo a tarefa de casa e brincando. A mãe fica envolvida com a arrumação da casa e com seus compromissos profissionais. Dormem por volta das 21:30h.

\section{A discursivização negativa: um caminho rumo ao diagnóstico}

A fim de iniciar a discussão, apresento abaixo um parecer descritivo redigido alguns meses depois de Susi ter ingressado na escola de Educação Infantil:

É extremamente inteligente, compreende tudo o que acontece ao seu redor, assimilando as propostas e regras das brincadeiras e as regras do grupo, o que não significa que ela as cumpra. Susi mostra-se bastante resistente quando é contrariada, falamos ou pedimos algo a ela. Várias vezes nada acontece. Cheguei a questionar se ela nos ouvia, porém, em seguida, quando resolvia, fazia tudo o que fora pedido.

É considerada a tagarela da turma, pois fala pelos cotovelos; repete tudo o que falamos e as vezes fico surpresa, parecendo um adulto chamando atenção dos outros, dando ordens e cobrando atitudes dos colegas. Susi nos mostra o quanto é esperta, o tempo todo tentando jogar conosco; quando precisamos chamar sua atenção, mostra-se bastante resistente e reage de forma que "não tô nem aî". Conversamos e explicamos várias vezes e nada; quando precisamos afastá-la um pouco do grupo para pensar o que fez, ela respondendo fala que não fará mais. Isto nos mostra que ela está bem consciente de seus atos e que realmente sabe o que está fazendo. Espero que nós adultos, casa/escola, que convivemos com a Susi possamos fazer um trabalho coerente para que ela não entre em conflito e choque de posturas. 
Nos demais aspectos do desenvolvimento, como motor, cognitivo e linguagem, ela apresenta um crescimento dentro do esperado para sua idade.

No $2^{\circ}$ semestre trabalharemos esquema corporal a fim de prepararmos para o desfralde, que será sua próxima e importante conquista.

(1) [Final do primeiro semestre de 2004 - parecer avaliativo da escola - grifos meus]

É possível, ao analisar o parecer acima, ir mapeando as representações que foram se construindo no decorrer da trajetória de Susi na escola. Aos 2 anos e 4 meses de idade, a menina, ainda fazendo uso de fraldas, já estava sendo discursivizada pela escola de forma depreciativa: "tagarela", "resistente", "dá ordens". Ressalte-se que, conforme palavras da educadora, ela já estava plenamente consciente de seus atos. Nesse contexto, cabe perguntar: como uma criança tão pequena pode estar plenamente consciente de seus atos? De que atos - entendidos aqui como erros - a educadora se refere? Pelo excerto, dá para ir desenhando a história de Susi, acreditando que essa imposição de rótulos foi se materializando em seu espírito desde a mais tenra idade.

A menina era chamada a pensar: "quando precisamos afastá-la do grupo para pensar...”. Ela começou a ser apontada e punida desde os 2 anos de idade. Tais consideraçóes convidam à reflexão: como uma criança se constitui em meio a esses discursos que já a apontam como "boa" ou "má" desde a época das fraldas? Vale destacar que hoje, aos 10 anos de idade, Susi apresenta sérios problemas de socialização com os colegas. Ela é excluída do grupo ao qual faz parte e sofre as consequências dessa exclusão. Além disso, ela se diz "agitada", "autoritária" e que tem dificuldades de aprendizagem. Mas como esse processo todo foi construído? Para conhecermos a resposta, temos de mergulhar nas interações vivenciadas por ela, para que possamos, pelo menos em parte, tentar reconstruir a realidade dessa criança e as razões que culminaram no diagnóstico de TDAH.

Para iniciar o trabalho de análise, recorro a Bakhtin:

Toda motivação do comportamento de um indivíduo, toda tomada de consciência de si mesmo [...] é a colocação de si mesmo sob determinada norma social, é, por assim dizer, a socialização de si mesmo e do seu ato. Ao tomar consciência de mim mesmo, eu tento como que olhar para mim pelos olhos de outra pessoa, de outro representante do meu grupo social [...]. (BAKHTIN, 2009, p. 86-87). 
Assim, como diz Bakhtin, a consciência de mim acaba levando à consciência de grupo de que ela é reflexo. ${ }^{7}$ E qual é a consciência do grupo ao qual Susi fez parte? Indo mais adiante no parecer avaliativo, é possível observar de que forma a escola convoca a família: "Espero que nós adultos, casa/escola, que convivemos com a Susi possamos fazer um trabalho coerente para que ela não entre em conflito e choque de posturas". O que significa, na visão da educadora, realizar um trabalho coerente para que Susi não entre em conflitos e choque de posturas? Acredito que todo o trabalho empreendido foi justamente o de colocar a criança em conflitos. Ao afastá-la do grupo, ao punila, ao convocar a família a se atentar às características individuais da filha - que só se transformam em "problemas" no contexto escolar - a escola frequentada pela menina agiu desestabilizando os familiares (e a própria aluna), deixandoos em situação de insegurança e gerando os tais conflitos que desejava inibir. Ao final do parecer, quando se diz que "nos demais aspectos está tudo dentro do esperado", confirma-se, enfim: há algo de errado. Inicia-se a construção de uma "patologia".

Freitas (2007), ao olhar a Educação sob uma ótica bakhtiniana, realiza algumas perguntas, que vão ao encontro das minhas próprias questóes no que diz respeito às relações estabelecidas entre alunos e professores no espaço da escola. Nessa direção, a autora pergunta: quem é o aluno para o professor? É um objeto sobre o qual se derrubam impressóes ou um sujeito com o qual se compartilham experiências? $\mathrm{O}$ aluno é alguém a quem o professor não concede o direito de se expressar, de ser autor de si mesmo? Ou sua voz apenas é reconhecida quando espelha a do seu mestre? Ainda, a sala de aula é um lugar de uma só voz ou um local onde diferentes discursos se intercruzam? O professor fala a um aluno abstrato ou a um sujeito situado histórica e socialmente? "Educar não é homogeneizar, produzir em massa, mas produzir singularidades. Deixar vir à tona a diversidade de modos de ser, de fazer, de construir: permitir a réplica, a contrapalavra" (FREITAS, 2007, p. 147).

Mas, em vez disso, Susi foi silenciada, posta de lado - no "cantinho do pensamento", apontada, recriminada desde muito cedo. "Entendia as regras, mas não significava que as cumpria”, conforme a professora. A criança era tida

\footnotetext{
${ }^{7} \mathrm{O}$ autor entende que é impossível analisar o conteúdo da consciência como algo universalmente humano, distante da relação entre o $e u$ e o $t u$. É na fronteira do eu com o outro, ou seja, no ponto de convergência, que a consciência pode ser compreendida (BAKHTIN, 2003).
} 
como "resistente". O que tal resistência poderia significar? Um desafio à autoridade do professor? Quais são as consequências das ações pedagógicas para a criança e sua família?

A mãe refere que ia buscar a filha e ela estava sempre lá - no cantinho do pensamento: "A Susi ficava no cantinho sentada... eles chamavam cantinho do pensamento, e quando chegou o segundo semestre desse ano começou a me dar uma coisa... o que é você pegar seu filho na escola e todo o dia receber... e ela [a professora] falava... e falava... e falava".

Durante todos os primeiros anos de sua vida, Susi foi convocada a "pensar" sobre suas ações. Esse pensar nada mais é do que uma forma de punição que se estabelece na escola. Em Vigiar e Punir, Foucault (2009) esquadrinha o nascimento do sistema penal francês e formas de punição de infratores, analisando como esse sistema de controle foi se alterando da época clássica até os tempos da modernidade. Assim, em uma era anterior, as ofensas ao rei eram punidas com castigos corporais: esquartejamento, queimação, enforcamento, tudo em prol de uma purificação da alma por meio do sofrimento sentido no corpo. A estratégia do poder soberano dá lugar a uma estratégia disciplinar, que conduz a formas mais brandas de punição, entendidas aqui como formas de encarceramento. De qualquer forma, em qualquer época, o corpo sempre foi alvo de poderes muito apertados, por onde lhe são impostas limitaçóes, proibições, obrigações. Foucault chama de "disciplinas" os métodos que propiciam o controle das operaçóes do corpo, que lhe obrigam a uma relação de docilidade por meio da sujeição de suas forças.

Sempre existiram muitos "processos disciplinares" nos conventos, nos exércitos, mas no decorrer dos séculos XVII e XVIII tais processos tornaram-se, segundo Foucault (2009), fórmulas gerais de dominação. Diferentemente da escravidão, que se pautava na posse do corpo, e da domesticidade, estabelecida na dominação de um patrão a seu empregado, o momento das disciplinas é quando nasce uma arte do corpo humano, que visa não apenas o aumento de suas habilidades ou o aprofundamento de sua sujeição, mas uma política de coerçóes, que implica uma manipulação calculada de seus gestos, de seus comportamentos. O corpo humano penetra em uma mecânica do poder. "A disciplina fabrica assim corpos submissos e exercitados, corpos dóceis [...] A invenção dessa nova anatomia política não deve ser entendida como uma descoberta súbita, mas como uma multiplicidade de processos muitas vezes mínimos [...]. Encontramo-los em funcionamento nos colégios, muito cedo"(FOUCAULT, 2009, p. 133-134). Para o autor, a essência de qualquer sistema disciplinar funciona como um mecanismo 
penal. E cita La Salle que, em 1828, dizia: "Pela palavra punição, deve-se compreender tudo o que é capaz de fazer as crianças sentirem a falta que cometeram, tudo o que é capaz de humilhá-las, de confundi-las... uma certa frieza, uma certa indiferença, uma pergunta, uma humilhação, uma destituição de posto" (FOUCAULT, 2009, p. 172).

Foucault (2009) assinala que a disciplina traz consigo uma forma específica de punir, que representa um modelo diminuto do tribunal. A penalidade ocorre quando há desvio, inobservância à regra. Desse modo, o efeito corretivo que se espera é o arrependimento, que é obtido pela dinâmica do castigo. "Castigar é exercitar" (FOUCAULT, 2009, p. 173). No parecer da escola, vimos uma alusão que se encaixa na consideração do autor: "ela respondendo fala que não fará mais". Fará o quê? Qual terá sido o delito de Susi? Quais as consequências de ser constantemente recriminada e castigada?

A seguir um recorte de um parecer avaliativo da escola, realizado em 20/ 05/2006, emitido quando Susi tinha 4 anos e 3 meses de idade:

A adaptação da Susi no grupo foi tranquila tendo em vista que já conhecia várias crianças da turma. Brinca com várias crianças e às vezes exerce sua liderança com autoritarismo brigando e dando ordens até mesmo para as educadoras. Em várias ocasiões faz queixa dos amigos para seus pais. Temos procurado contornar estas situações conversando e explicando-lhe como deve proceder.

(2) $[20 / 05 / 2006$ - parecer avaliativo da escola]

No parecer acima, temos um dado importante: Susi “exerce sua liderança com autoritarismo". Pelos excertos apresentados é preciso acreditar que a aluna possui uma capacidade de liderança, uma vez que manifesta os seus desejos tentando, conforme a professora, impor a sua vontade sobre a dos demais colegas e até mesmo da própria educadora. A questão que se coloca é que algumas atitudes são bem toleradas ao passo que outras não são. Uma criança considerada "obediente" é bem aceita. Uma criança que manifesta suas vontades não é. O espaço escolar, muitas vezes, não é dialógico por natureza, espaço de circulação de múltiplas vozes. A escola "tradicional" parece ser regida por uma única e exclusiva voz: a do professor. Sobre o monologismo, diz Bakhtin:

O monologismo nega ao extremo, fora de si, a existência de outra consciência isônoma e isônoma-responsiva, de outro eu (tu) isônomo. No enfoque monológico (em forma extrema ou pura), o outro permanece inteiramente apenas objeto da consciência e não outra 
consciência. Dele não se espera uma resposta que possa modificar tudo no mundo da minha consciência. O monólogo é concluído e surdo à resposta do outro, não o espera nem reconhece nele força decisiva. Passa sem o outro e por isso, em certa medida, reifica toda a realidade. Pretende ser a última palavra. (BAKHTIN, 2003, p. 348).

Em seu discurso autoritário, quem pensa diferentemente "dá ordens" e, desse modo, tem de ser silenciado, pois algumas escolas educam para a obediência e não para a negociação das diferentes ideias que se instauram em qualquer situação de grupo. O problema é que a domesticação para a obediência pode causar desequilíbrios nas crianças. Muitas delas reagem às formas impositivas de dominação. Os resultados podem ser observados nas próprias de salas de aula, que muitas vezes mais parecem campos de batalha entre alunos e professores do que espaço de pluralidade de vozes e socialização de conhecimentos. E nesse "jogo" os aparelhos disciplinares hierarquizam os bons e os maus sujeitos, como pondera Foucault:

Através dessa microeconomia de uma penalidade perpétua, opera-se uma diferenciação que não é a dos atos, mas dos próprios indivíduos, de sua natureza, de suas virtualidades, de seu nível ou valor. A disciplina, ao sancionar os atos com exatidão, avalia os indivíduos "com verdade"; a penalidade que ela põe em execução se integra no ciclo de conhecimentos dos indivíduos. (FOUCAULT, 2009, p. 174).

No jogo de poder estabelecido, em que se ditam desde cedo os bons e os maus, como Susi é discursivizada? Como alguém que exerce uma autoridade? E que, por isso, necessita ser punida? A professora explica a ela como deve agir: "Temos procurado contornar estas situações conversando e explicando-lhe como deve proceder". O que é o cantinho do pensamento senão um espaço de exclusão? A escola, muitas vezes, normaliza, impõe uma homogeneidade e quem ousa pensar diferente não pode fazer parte do grupo, porque no grupo todos devem obedecer e proceder à mesma maneira.

Para Foucault (2009), a penalidade hierarquizante serve para o exercício de uma pressão constante, "para que se submetam todos ao mesmo modelo, para que sejam obrigados todos juntos à subordinação, à docilidade, à atenção nos estudos e nos exercícios, e à exata prática nos deveres e de todas as partes da disciplina. Para que, todos, se pareçam"(FOUCAULT, 2009, p. 175). Nesse espaço de massificação, de sublimação das singularidades, de imposição de uma única voz, de castigo, de exclusão, como a criança se constitui? Como a criança, 
que não se apresenta da forma esperada, caso de Susi, se constitui? Nos dias de hoje a menina permanece sozinha na hora do intervalo das aulas ${ }^{8}$ e, quando questionada sobre a razão de não estar brincando com as outras meninas, diz que é porque ninguém gosta dela, que ninguém quer brincar com ela. Desde os 2 anos de idade ela era excluída do convívio com os demais colegas de sala; permanecia de lado a "refletir" sobre seus "atos errados" e, na atualidade, sofre as influências recebidas desde sempre na escola. Ela não se sente parte do grupo. Ela não faz parte do grupo.

Convém ressaltar que, como já dito, as condições impostas à criança também o são à sua família, que é chamada a perceber os "problemas" que só se evidenciam no espaço escolar. A palavra da escola muitas vezes gera insegurança para os pais - discussões acirradas acerca do que deve ou não ser feito; pode alterar o olhar da família sobre a criança. Assim, muitas das ações da criança podem vir a sofrer desvios de interpretação por parte dos familiares, que, desestabilizados, não sabem como proceder. Conflitos são gerados também quando pai e mãe apresentam divergências relacionadas às atitudes que devem ser tomadas; se um deles adere mais ao discurso da escola e o outro adere menos, ou seja, se a criança encontra-se em meio a disposições familiares diferentes.

Diante do discurso que aponta, que homogeneiza, está o pai de Susi, que convocado, responde:

A Susi percebeu o objetivo do projeto Histórias Infantis, cita em suas falas personagens e trechos destas histórias. A iniciação ao letramento está sendo absorvida com interesse. Susi demonstra isto identificando a letra inicial de seu nome em todos os lugares onde ela a encontra. Já estamos conscientes de seu comportamento autoritário, conduzindonos em busca de auxílio especializado nesta área.

(3) $[05 / 06 / 2006$ - comunicado escrito do pai à escola - grifo meu]

Assim, no encontro de consciências, a família entra em um círculo de incertezas. A escola muitas vezes não consegue lidar com as diferenças entre as crianças, principalmente com aquelas que se mostram "resistentes", ou seja, que apesar dos eternos esforços das educadoras mostram ainda suas próprias

\footnotetext{
${ }^{8}$ Vale comentar que a exclusão social é um dos "sintomas" do chamado TDAH. Mas há de se questionar: esse "sintoma" é decorrente de uma alteração cerebral ou de uma aprendizagem social?
} 
vontades (o sujeito é social e ao mesmo tempo singular, conforme Bakhtin). Se o "problema” persiste, à família é delegada a responsabilidade de resolvê-lo. E nessa direção, a família sinaliza a busca por um profissional especializado; o "problema" deixa de ser da ordem da educação e passa a ser da ordem da saúde. Alguns profissionais da educação, alheios aos aspectos do desenvolvimento infantil, realizam "diagnósticos" ainda no espaço escolar. Se a criança pouco brinca, pouco fala, pode ser "autista"; se muito brinca, muito fala, apresentase resistente e desobediente, pode ser "hiperativa"; se troca as letras ao escrever é "disléxica"; se tem dificuldades para aprender é "deficiente mental". É nesse universo instaurado por um discurso higienizante que os alunos se constituem.

Dando continuidade à trajetória escolar de Susi, agora com 5 anos e 3 meses de idade, as queixas que eram "apenas" comportamentais, até em virtude da pouca idade, começam a se direcionar também ao campo da aprendizagem. Nesse sentido, a escola agora fala em "concentração", "desenhos com poucos detalhes". Inicia-se a nova "saga" e o objetivo agora é imputar à criança mais uma condição: a de portadora de distúrbios de aprendizagem. Foi nessa fase que os pais buscaram uma avaliação psicológica para a filha. Vejamos:

Em seus desenhos representa elementos soltos pelo espaço do papel, faz bonecos e sol, com poucos detalhes. Não compõe muitas cenas. [...] Conversa bastante e desconcentra-se rapidamente durante atividades individuas de escrita e desenho. Susi aprecia atividades de dança, música e representação corporal.

(4) $[31 / 05 / 2007$ - parecer avaliativo da escola - grifo meu]

Cabe observar, neste ponto, como Susi é mesmo "resistente", só que, no meu modo de ver, no bom sentido do termo. De início resistia à imposição de regras, tentando negociar o cumprimento dessas regras com argumentos para suas ações consideradas "inadequadas". Nesta fase, desconcentra-se marcando seu descontentamento com atividades fora de contexto e sem sentido para ela. Vale lembrar que a menina era filha de pedagoga, oriunda da classe média, e seus pais, ao que parece, eram muito participativos em relação aos aspectos educacionais. Além disso, a mãe mencionou que o pai era um leitor ávido, e sua escrita revela, de fato, seu bom "nível" de letramento. ${ }^{9}$ Desse modo, nessas condiçôes, era de se esperar que a criança tivesse sido talhada para

${ }^{9}$ Tive acesso a duas comunicaçôes escritas do pai à escola. 
a escola. A escola, aos filhos das classes médias e altas, é algo intrínseco à natureza humana. A necessidade da escola é algo que nem se discute, simplesmente se aceita. Entretanto, mesmo assim, apresentando todas as condições, em princípio, satisfatórias para o seu bom desenvolvimento na escola, Susi demonstrava um "comportamento de fuga", quer dizer, parecia alheia à sala de aula. Há uma série de questôes que se colocam nesse caso.

Em primeiro lugar, segundo Vygotsky (2010), o fenômeno da desatenção ocorre nessa idade. Mas por ora vou desconsiderar tal variável e imaginar que as demais crianças estavam todas "quietas" a escrever e desenhar e apenas Susi "desconcentrava-se rapidamente". Na sequência, há de se lembrar que desde que tinha 2 anos de idade ela estava inserida em um círculo de interações negativas na escola. Isto é, há 3 anos a menina ouvia que seu comportamento era inadequado e era constantemente advertida sobre isso e excluída da convivência de seu grupo a fim de refletir sobre seus "atos ruins". Assim, formulo a hipótese de que, a essa altura, sua subjetividade estava bastante abalada, e, além disso, a aceitação da escola para ela poderia já estar comprometida, uma vez que aquele espaço não era de negociação de sentidos nem de boa convivência. É possível supor, então, que a aluna foi afetada por essas interações e começou a manifestar desinteresse pela escola e pelas atividades realizadas naquele local. Por fim, acrescento que as atividades realizadas eram descontextualizadas. Tive acesso à pasta da aluna e nesta pude constatar que as atividades de escrita se restringiam a exercícios de "escrever à sua maneira" palavras ao lado de nomes de figuras dadas. Outras sugeriam que se escrevessem palavras e frases que seriam ditadas pela professora.

É absolutamente natural que atividades como essas conduzissem a uma rápida desconcentração. Os alunos são inseridos em práticas pedagógicas nada desafiadoras e muitos respondem de forma "desmotivada", "desinteressada", "desatenta”. Lembramos que Vygotsky (2010) diz ser crucial para qualquer aprendizagem promover o interesse dos alunos. Como atividades pautadas em ditados de palavras e frases podem despertar o interesse das crianças? No máximo conduzem a uma sujeição.

Em setembro de 2007, aos 5 anos e 7 meses, outro parecer:

Reconhece poucas letras do alfabeto, apesar das frequentes atividades e brincadeiras relacionadas ao letramento. Em atividades de escrita espontânea faz uso apenas do repertório de letras de seu nome, fazendo poucas relações com o som das letras nas palavras. [...] Em suas relações afetivas continua exercendo liderança de forma excessiva, discutindo 
até mesmo com educadores e auxiliares. Tenho sido firme com ela buscando cumprir os combinados e limites.

(5) $[25 / 09 / 2007$ - parecer avaliativo da escola - grifo meu]

É possível notar que a escola insiste em conduzir a família a acreditar que a filha está com problemas para se apropriar da linguagem escrita, apesar das frequentes atividades relacionadas ao letramento. Isso significa que a escola está cumprindo a sua função de ensinar, mas Susi não está cumprindo a sua de aprender? Ocorre que a menina tinha apenas 5 anos de idade e o fato de reconhecer poucas letras do alfabeto deveria ter sido encarado de forma processual. Há de se perguntar por que muitas escolas são tão apressadas ao convocar a família a se atentar ao que, na visão dos educadores, a criança ainda desconhece. Por que não sinalizam apenas suas conquistas? No parecer acima, poderia ser dito: "Já reconhece e utiliza várias letras do alfabeto, especialmente as letras de seu nome, fato inerente ao processo de alfabetização".

Enfatiza-se, ainda, que a escola menciona a palavra "letramento", mas possivelmente não compreende o significado desse termo, ou, pelo menos, desconhece a sua face ideológica. Penso, e pude constatar ao observar as atividades, que o letramento desenvolvido pela escola é o autônomo e, dessa forma, é natural que alguns "problemas" surjam, em especial quando a criança já apresenta conflitos relacionados ao papel da escola em sua vida.

Concordo com Kleiman (2008) quando diz que a escola dita tradicional não se preocupa com o letramento como prática social, vinculado ao uso da escrita. A escola, em geral, só se preocupa com a aquisição do código escrito pela criança, processo esse concebido em termos de competências individuais, fundamental para o sucesso escolar. Dessa forma, é fácil compreender a dificuldade enfrentada por muitas crianças para desenvolver qualquer tipo de interesse nas "atividades de letramento" propostas.

O mais complicado é que algumas escolas de forma alguma sinalizam qualquer responsabilidade escolar para eventuais "dificuldades" de aprendizagem. Se a criança apresenta um "ritmo" não esperado já se realizam encaminhamentos para especialistas para que se descubra onde se encontra o problema da criança: É cerebral? É emocional? É mental? O problema nunca é o da escola, do professor mal preparado, das práticas nada significativas. $\mathrm{O}$ fato se complica quando os profissionais de saúde são chamados e compactuam com a visão distorcida diante das possibilidades do aluno. O que prevalece em situação de clínica são profissionais que submetem o paciente a uma série de testes avaliativos padronizados, que terminam por aniquilar de vez qualquer 
possibilidade de normalidade. A criança, estagnada em meio a essas relações sociais, recebe o diagnóstico.

\section{O diagnóstico}

Susi acabou sendo submetida à avaliação psiquiátrica e, como mencionado anteriormente, aos 6 anos de idade recebeu o diagnóstico de TDAH:

P. (pesquisadora). A Susi tem o diagnóstico?

Mãe. Tem. A Susi passou por... além de... primeiro eu tive uma resistência em relação a essa possibilidade... [...] daí eles me indicaram para um médico, que é psiquiatra infantil, daí esse psiquiatra pediu pra ela fazer testes com psiconeuro...

P. Neuropsicólogo?

Mãe. É. Neuropsicólogo. Daí ela fez os testes e ele constatou que era isso aí, que o diagnóstico era esse mesmo: TDAH. Daí ela passou a fazer tratamento... acompanhamento com psiquiatra [...]

(6) [Entrevista com a mãe da criança]

Enfim, o diagnóstico. Segundo Moysés (2001), o diagnóstico não é o suficiente para resolver o problema, mas pelo menos serve para tranquilizar os conflitos que uma criança-que-não-aprende-na-escola gera. No caso de Susi, além disso, uma criança-que-não-se-comporta-bem-na-escola. Com apenas 6 anos de vida! Duplamente rotulada (na escola e na clínica) simplesmente porque ousou ser ela mesma; permitiu-se resistir, ao menos em parte, às cruéis investidas recebidas no espaço da escola. Posta no canto a tomar consciência de suas açóes desde muito cedo; agora, finalmente, recebe a sentença definitiva. Susi recebeu o diagnóstico de um transtorno psiquiátrico, pois tentava manifestar os seus desejos, não reconhecia todas as letras do alfabeto, realizava desenhos com poucos detalhes, imitava a professora e brigava com os amigos. Nos termos de Moysés (2001, p. 46):

Rotulada, a criança resiste, luta contra o preconceito, até que o incorpora. Resiste e incorpora em sua vida inteira, não em fragmentos de vida. Não é apenas na escola que se torna a criança que não sabe; a incapacidade adere a ela, infiltra-se em todas as facetas, todos os espaços da vida. Deixa de ser incapaz na escola para se tornar apenas incapaz. 
Expropriada de sua normalidade, sofre.

Sofre ao resistir, sofre ao desistir.

Sofre tão intensamente, pelo sutil processo de expropriação violenta, que nos atinge a todos nós que nos dispomos a olhá-las, a dar-lhes voz, a respeitar sua individualidade.

Diz a autora que crianças normais vão se transformando em crianças doentes. Até que, doentes, necessitam de atendimentos na área da saúde: consultas com psicólogos, psicopedagogos, fonoaudiólogos, psiquiatras.

Vale dizer que Susi foi vítima do efeito-zumbi, pois, segundo a mãe, a filha ficava "meio parada" sob efeito do remédio, revelando ainda: "tava pra me dar um troço de ver minha filha daquele jeito". Ressalta-se que mesmo medicada desde os 6 anos de idade, Susi só conseguiu ser alfabetizada no terceiro ano, como já dito, e por razões delegadas à esfera afetiva/educacional:

Susi: A única professora que eu fui com a cara dela, que eu gosto dela realmente, é a Jaque...

P. E como é que é a Jaque? Me conta?

Susi: A Jaque é doce... Ela ensina bem as pessoas [...] Às vezes eu falo: "Jaque, não tem uma vaga pra mim de novo?"

(7) [Entrevista com a criança]

\section{Considerações finais}

Pela análise empreendida neste estudo é possível refletir sobre algumas questões: Por que estamos entre os últimos lugares no ranking das competências em leitura, conforme o PISA (Programa Internacional de Avaliação de Estudantes), e entre os primeiros no uso de medicação estimulante? Por que, mesmo assim, consumindo um remédio que teria por finalidade normalizar a atenção e o comportamento, continuamos presos ao fato de que as crianças são "desatentas", "desinteressadas", "indisciplinadas", e que, além disso, têm "dificuldades” para aprender? Será que um medicamento poderá resolver o problema da Educação?

Este estudo aponta que a má qualidade do ensino no Brasil está atrelada não somente às práticas pedagógicas pouco eficazes, mas às percepções distorcidas que alguns professores nutrem acerca de sua clientela. Muitas escolas 
não acolhem a diversidade manifesta nos modos de ser, pensar e agir dos alunos e tentam impor um comportamento em conjunto. Os educadores que, por sua vez, aderem a esse movimento de higienização das diferenças no espaço da escola, terminam por adotar certas estratégias, entre elas a exclusão e punição dos alunos considerados mais resistentes à imposição de regras dadas a priori. Entre essas medidas, encaminham os alunos para profissionais de saúde para resolverem o problema que não é da Educação, segundo esses educadores, mas do aluno, de distúrbios/transtornos que o acometem. Nesse sentido, comportamentos mais ativos, desatenção e desinteresse frente às atividades propostas pela escola, recusa em realizar os exercícios em sala de aula, instabilidades (processuais) no percurso de apropriação da escrita, conflitos com os colegas, ou, ainda, certas tendências que poderiam ser modificadas mediante atitudes educativas, começam a ser encarados como "sintomas".

As ações infantis, quando entendidas como "sintomas", podem gerar um processo de discursivização desfavorável ao bom desenvolvimento do aluno, uma vez que a criança, submetida a discursos estigmatizantes, poderá internalizar parte desses discursos e ter a subjetividade e aprendizagem afetadas em meio a esse processo. Tal consideração pode ser observada no estudo do caso aqui apresentado, uma vez que a voz da escola revela uma visão depreciativa sobre a aluna. Como consequência, entre outras, ela teve/tem problemas de socialização e apresenta a autoestima rebaixada. Além disso, Susi teve dificuldades para se alfabetizar - sem ter qualquer alteração orgânica - que, por ventura, justificasse uma razão para a dificuldade apresentada.

Convém assinalar que compreender a diversidade como um fato inerente a todos os seres humanos que vivem em sociedade, não implica deixar de tomar medidas quando necessário. Mas tais medidas devem se distanciar de imposições e castigos, uma vez que essas atitudes "educativas" não alcançam o resultado almejado. Desse modo, a escola, ao detectar no aluno uma tendência considerada antissocial, pode ensiná-lo a negociar seus desejos e opiniōes, a compartilhar, a dividir, e é na relação social (mediada pelo educador) que as crianças ganham oportunidades de aprender essas regras interacionais. Só que punindo o aluno, a escola transforma uma diferença em delito. A criança poderia aprender a negociar/dialogar, mas aprende que comete erros e que os comete por questóes constitutivas a ela (cerebrais/patológicas).

Esta pesquisa mostra a necessidade de se promover a implementação de recursos para a melhoria das condições de formação dos professores, proporcionando-se, na escola, um espaço de inclusão e aprendizagem, ou seja, 
de despatologização da educação. Os professores poderiam ser levados a entender que em contextos significativos de uso da língua, por exemplo, os alunos manifestam interesse e, com isso, aprendem. Nesse contexto, os "sintomas" de desatenção, de hiperatividade e de desinteresse, seriam substituídos por outros sinais: comprometimento, avanço, apropriação de conhecimentos. Modificar-se-ia, adicionalmente, o olhar do professor sobre o aluno e do aluno sobre o professor, pois haveria um comprometimento mútuo; e o espaço de indisciplina, de castigo, de obrigação, de exclusão e de sofrimento cederia lugar a outro: de encontro entre sujeitos, de diálogo, de troca, de parceria. Só assim, por meio do empoderamento do profissional da educação, é que poderemos nos desprender de paradigmas pautados pela doença e nos engajar, todos, em prol de uma transformação social.

\section{Referências}

BAKHTIN, M. Marxismo e filosofia da linguagem. São Paulo: HUCITEC, 2006. BAKHTIN, M. Estética da criação verbal. São Paulo: Martins Fontes, 2003.

BAKHTIN, M .O Freudismo. São Paulo: Perspectiva, 2009.

BARKLEY, R. Transtorno de Déficit de Atenção/Hiperatividade: manual para diagnóstico e tratamento. Porto Alegre: Artmed, 2006.

CONNOR, D. F. Outros medicamentos. In: BARKLEY, R. Transtorno de Déficit de Atenção/Hiperatividade: manual para diagnóstico e tratamento. Porto Alegre: Artmed, 2006, p. 670-690.

FOUCAULT, M. Vigiar e Punir. Petrópolis: Vozes, 2009.

FREITAS, M. T. Bakhtin e a psicologia. In: FARACO, C. A.; TEZZA, C.; CASTRO, G. (Org.). Diálogos com Bakhtin. Curitiba: Editora UFPR, 2007, p. 141-160.

KLEIMAN, A. Modelos de letramento e as práticas de alfabetização na escola. In: p. 15-64. . Os significados do letramento. Campinas: Mercado de Letras, 2008,

LURIA, A. R. Vygotsky. In: VYGOTSKY, L. S.; LURIA, A. R.; LEONTIEV, A. N. Linguagem, desenvolvimento e aprendizagem. São Paulo: Ícone, 1988, p. 21-37. LURIA, A. R. Curso de psicologia geral. Volume III. Rio de Janeiro: Civilização Brasileira, 1991.

MOYSÉS, M. A. A institucionalização invisivel: crianças-que-não-aprendem-naescola. São Paulo: Mercado de Letras, 2001.

ROHDE, L.; MATTOS, P. Princípios e práticas em TDAH. Porto Alegre: Artmed, 2003. 
SILVA, M. L. Q. Desempenho em leitura e escrita de alunos com diagnóstico de TDAH. Mestrado em Educação. Curitiba: UFPR, 2006.

VYGOTSKY, L. S. A formação social da mente. São Paulo: Martins Fontes, 1984. VYGOTSKY, L. S. Psicologia pedagógica. São Paulo: Martins Fontes, 2010.

WAJNSZTEJN, R. O Transtorno de Déficit de Atenção e Hiperatividade e suas implicações no processo de aprendizagem. Curso de curta duração. CEFAC, 2012.

Recebido em 14/03/2013. Aprovado em 02/09/2013. 